\title{
SURGICAL TREATMENT OF PULMONARY METASTASES FROM PRIMARY TUMOURS OF BONE
}

\author{
Rodney Sweetnam and Keith Ross, London, England \\ From The Middlesex Hospital, London
}

Interest in lung resection for metastatic malignant disease has steadily increased since it became apparent that in carefully selected patients the results in terms of prolongation of life could be surprisingly good. Indeed the outcome after such resection for metastases of all kinds compares favourably with those to be expected following resection of primary tumours of the lung (Smith 1963, Clagett and Woolner 1964).

Success in this type of surgery more often follows resection of solitary deposits from epithelial tumours, particularly those of the large bowel and genito-urinary tract. Sarcomata

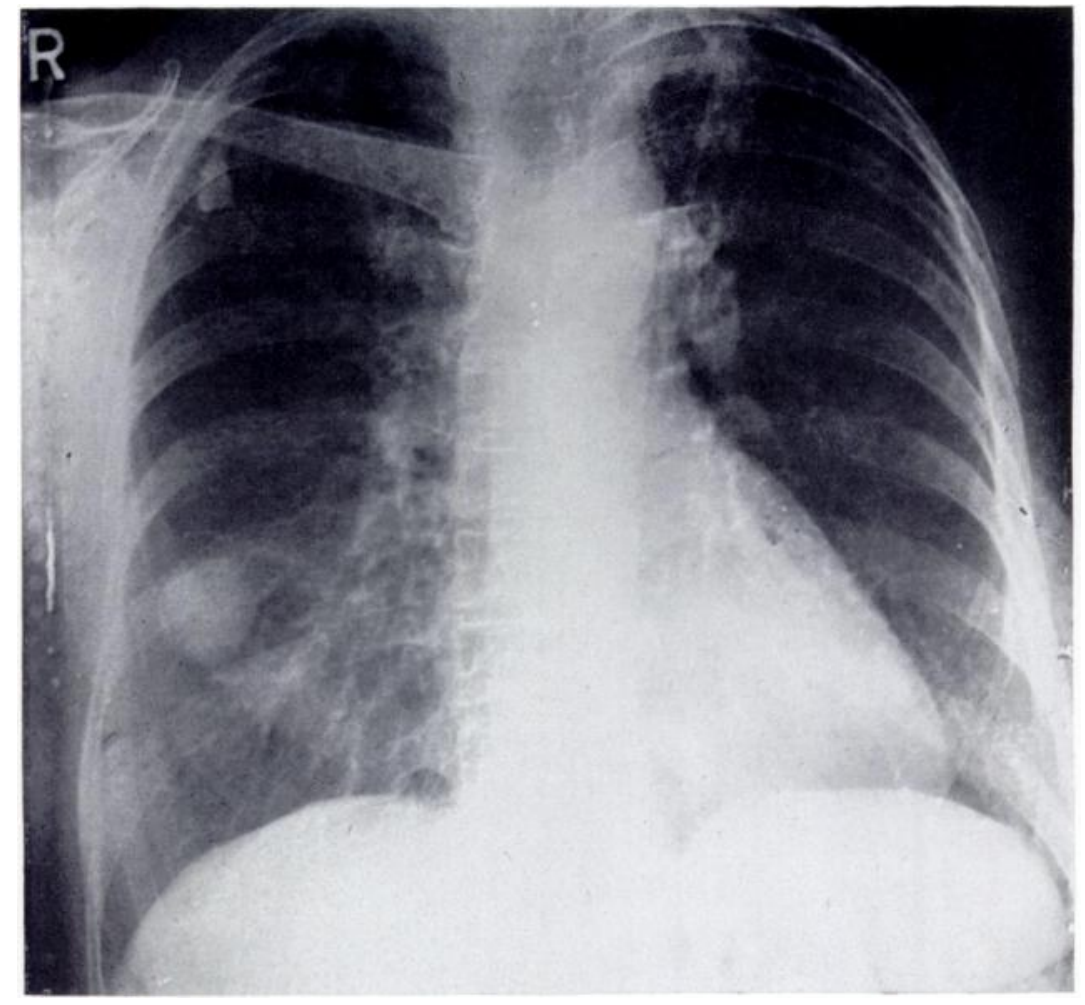

FIG. 1

Case 11-Metastasis following forequarter amputation. Patient died without necropsy evidence of malignancy seven and a half years after pulmonary resection.

on the other hand usually produce so many metastases that resection is unthinkable. Primary tumours of bone are no exception, for the great majority produce multiple deposits which are quite inoperable. Nevertheless there remain some patients in whom a single lung secondary develops which is not swiftly followed by others and in whom we should at least consider the possibility of resection (Fig. 1). 
It is with this small group of patients with primary tumours of bone that this paper is concerned, and we shall show that in carefully selected patients there is a place for resection of the lung secondary and that sometimes the operation is apparently life-saving.

Rather surprisingly little has been written about this form of treatment of secondary deposits from bone. Of course, such bone primaries are in any case uncommon and those with suitably solitary metastases must be rare. Therefore experience in any one centre of treatment, however wide its net, is likely to be small. It is for this reason that we have included in this group not only those patients treated at The Middlesex Hospital but also others treated in a similar way from elsewhere in the United Kingdom. Our twelve patients are highly selected, but they represent all those that we have been able to find who have been treated in this way, successes and failures alike, and thus should provide an indication of the results to be expected from pulmonary resection. The group is in no sense controlled, and it is therefore quite possible that the results may have a bias towards success. However, that success can be achieved is important in itself.

In 1947 Alexander and Haight reported the first pulmonary resections in patients with bone tumours. Their series of nineteen patients with various tumours included two with bone primaries. More recently Moersch, Bickel and Clagett (1963), in a review of 165 lung resections for all varieties of metastatic tumour, included eleven with primary tumours of bone, two of whom had survived for more than seven years at the time of their report. The first operation in this series, and possibly the first in Great Britain, was performed at The Middlesex Hospital in 1951.

\section{INDICATIONS AND SELECTION FOR LUNG RESECTION}

Various opinions have been expressed concerning the indications for, and the timing of, lung resection, but at this stage while the reported number of patients remains small, dogmatic criteria for either cannot be stated. It is possible, however, to draw certain conclusions which at present appear reasonable but which may in the light of further experience require modification. Clearly three conditions must pertain before resection is even considered: the primary growth must have been entirely eradicated; there must be no other detectable metastases; and the lung lesion must appear to be solitary.

The most difficult decision is the timing of resection. It may be wise to advise a period of observation after the lung lesion is first discovered-three months was suggested by Clagett and Woolner (1964) - the argument being that in favourable cases nothing is lost and an unnecessary operation avoided if the early lesion proves to be the first of many to appear in quick succession. Although there is obvious wisdom in this counsel, human nature in the absence of radiological evidence of other deposits may tend to lead one to earlier lung resection. Indeed, apart from one's natural desire to rid the patient of his second lesion as soon as possible, there is the obvious alternative argument that even solitary metastases often grow quite quickly and the smaller they are the easier it is to obtain a wide clearance.

A further fact on the side of early resection is the question of diagnosis, for it is not always possible to be absolutely sure if the solitary lung lesion is a true metastasis. Although obviously not a very important factor, the point is well illustrated in one patient in this series (Case 9), a patient of Mr Philip Newman, who developed another chest shadow four years after resection of a solitary pulmonary metastasis from an undoubted chondrosarcoma of the femur. The second resected lesion proved to be a primary bronchial carcinoma. The patient is still alive eight years after this second primary was removed.

\section{THE PRESENT SERIES}

All patients with a primary bone tumour known to have had their pulmonary metastases removed have been included. Our search throughout the United Kingdom for such cases has not been exhaustive, but the group probably represents a large proportion of such cases in thiscountry.

VOI. 49 B, NO. 1, FEBRUARY 1967 


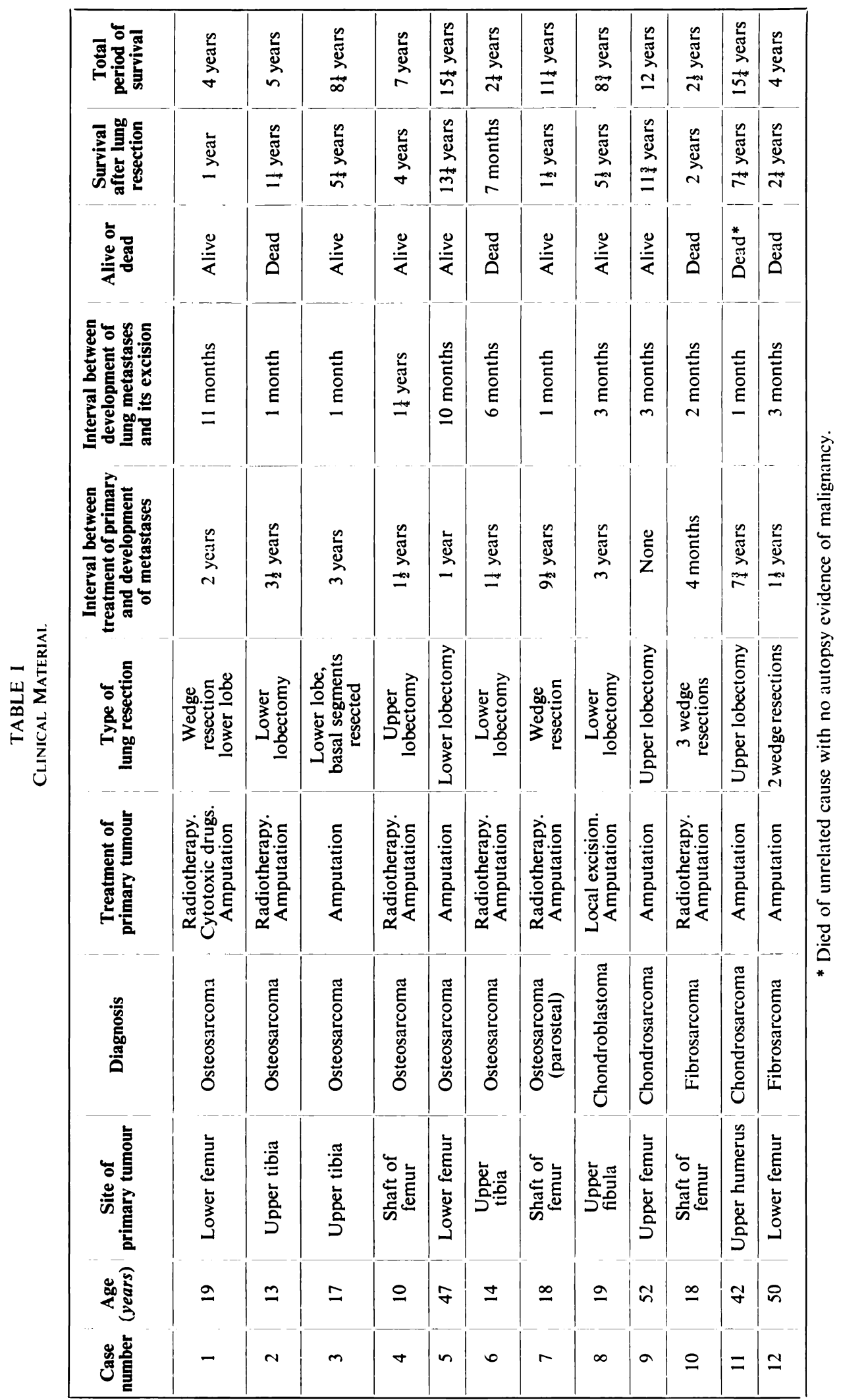

THE JOURNAL OF BONE AND JOINT SURGERY 
There are twelve patients (Table I), seven treated for osteosarcoma, two for chondrosarcoma, two for fibrosarcoma and one for malignant chondroblastoma. Histological confirmation of the diagnosis has been obtained in each patient, but the original radiographs were unobtainable in five patients. The average age of those with osteosarcoma was nineteen years, with chondrosarcoma thirty-six years, and with fibrosarcoma thirty-four years. The patient with malignant chondroblastoma was twenty years of age.

\section{RESULTS}

Of the twelve patients, seven are alive and another (Case 11) died over seven years after pulmonary resection without necropsy evidence of malignancy. Of the survivors, the period of follow-up since the lung resection has been less than four years in only two, and the average is six years seven months.

The average period of survival after pulmonary resection in the four patients who died from the tumour was one year and seven months, but as the average interval between treatment of the primary growth and the development of metastases was one year and nine months, this relatively long survival may simply be due to slow tumour growth.

Osteosarcoma-There were seven osteosarcomas including one parosteal osteosarcoma. Five are still alive. The other two died at seven months and seventeen months. Of those who are still alive, the period since pulmonary resection varies from one year to thirteen years and five months, the average being just over five years (Fig. 2).

Chondrosarcoma-There were two patients with chondrosarcoma, one of whom is alive eleven years and ten months after removal of the lung secondary. The other died of an unrelated cause seven years and five months after resection of the metastatic lesion. A careful search was made at necropsy but no evidence of residual tumour could be found.

Fibrosarcoma-Both patients with fibrosarcoma died from the disease in spite of resection of the lung metastases. The first died two years and one month and the other two years and three months after resection. Although radiographs suggested no more than one metastasis in the first, operation revealed three separate deposits, each of which was resected locally. The patient in Case 12 was known to have two deposits before operation. Both lesions were also resected locally.

Chondroblastoma-This unusual and apparently

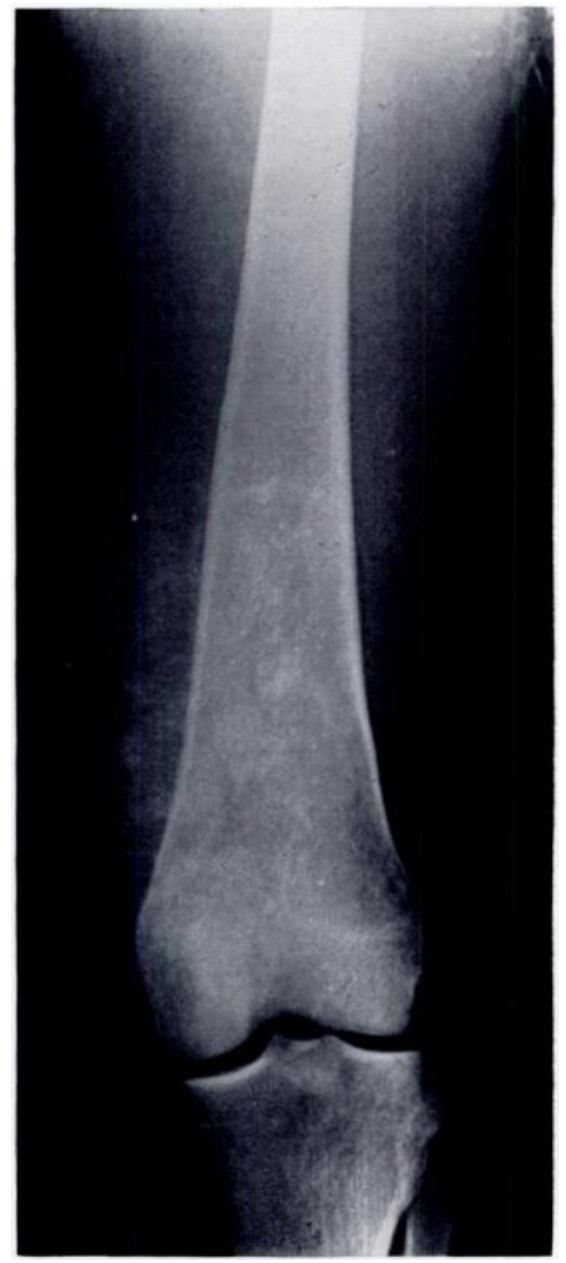

FIG. 2

Case 1-Aged 19 years; osteosarcoma of femur. Developed pulmonary metastasis twenty months after amputation through the hip. Alive without other metastases one year after pulmonary resection. malignant variety of chondroblastoma was identical in histological appearance with the primary growth in the head of the fibula. The patient, aged nineteen, is still alive five years eight months after pulmonary resection.

VOL. 49 B, NO. 1, FEBRUARY 1967 


\section{DISCUSSION}

The size of this series is too small to allow one to draw anything but the broadest conclusions. The most important of these, however, is that in carefully selected patients presenting with a solitary pulmonary metastases its removal conveys a reasonable chance of survival. Out of these twelve patients, only four have so far died of the disease and the average follow-up of the others since the lung operation is over six years.

In such a series there must be a possibility that one is dealing with quirks of pathology, and indeed there can be no doubt that some of the tumours are atypical in clinical course; for example, in the very long interval between primary treatment and the development of pulmonary metastases in Cases 2, 3, 7,8 and 11. The late development at the age of forty-seven of an otherwise typical osteosarcoma in Case 5, and the extremely rare malignant variety of chondroblastoma in Case 8, are likewise atypical. Nevertheless, although there is always scope for argument in the exact terminology of all primary bone tumours and a significant proportion must always remain "atypical," there can be no doubt of the malignant nature of all the tumours in this series. All have metastasised to the lung and the histological similarity between primary and secondary has been confirmed.

It seems, therefore, that the resection of solitary metastatic deposits in the lung from primary tumours of bone has a definite place in the management of such cases. The present series suggests that success is more likely to follow resection in osteosarcoma and chondrosarcoma than in fibrosarcoma, and that the interval between the primary growth and the development of metastases has little, if any, significance in relation to ultimate survival. Unfortunately, it seems that only a very small proportion of tumours produce a solitary metastasis which is not rapidly followed by others. Indeed there may well be some inherent distinction in the behaviour and composition of such tumours which is not apparent from present methods of histological examination. This, however, is no reason for leaving the secondary in the lung untreated, for it remains a malignant tumour with both the local and general invasive powers of its parent primary.

Having established a case for pulmonary resection and accepted the criterion that the primary must have been eradicated, we face the more difficult definition of the second condition, that the metastasis must be solitary. Sometimes there may be two apparently discrete metastases which may not be followed rapidly by others and which may seem suitable for resection as in Case 12. Clearly the most important factor when considering suitability for resection in solitary or apparently discrete double metastases is the length of time or "waiting period" before surgery is advised. Sufficient time must have elapsed to allow the appearance of previously occult secondaries. It is in the judgement of the length of this waiting period that the greatest difficulty in selection lies.

These unfortunate patients, the majority of whom are likely to be children, must not be subjected to unnecessary further suffering; nor on the other hand must potentially suitable patients be denied adequate secondary surgery without too much delay. The present series gives us little guidance, for the average waiting period among the four patients who died of the disease was three months, whereas among those who survived, the average delay was only just under six months. However, four of these had the lung operations within three months; so no definite conclusion can be drawn from these figures alone. In the present state of our knowledge we believe that a waiting period of three months is reasonable, and this is now our practice. During this period no further metastases should have developed, and before resection a thorough search for occult deposits including tomography of the lung must have been carried out.

In spite of the most careful pre-operative investigation along the lines indicated, the thoracic surgeon may have to face grave disappointment in apparently favourable cases once the chest is open. Multiple seedling deposits, of insufficient size to show in the chest radiograph, may be found scattered throughout the lung or on the pleural surfaces. "Tertiary " deposits 
in lymph nodes may also be found. The precise surgical tactics adopted must obviously be dictated by the findings at thoracotomy, but lobectomy, with appropriate lymph node clearance, must be regarded as the ideal operation for the genuinely solitary metastasis. It is difficult to imagine a situation in which pneumonectomy would be justifiable unless a freak metastasis, remaining single, were to reach such a size that its bulk gave rise to symptoms demanding relief. Segmental and wedge resection, as may be seen from the results in this series, can be followed by long survival. These lesser procedures, not usually associated with the accepted principles of surgery for malignant disease in the lung, clearly have a place, particularly when more than one secondary deposit is present.

The small numbers in this series need no emphasis: they represent no more than a small proportion of all primary bone tumours, probably no more than one in thirty. Nevertheless, they are an important group, seemingly with a much better prognosis than their fellows, and in our opinion should be sought out without too much delay. The appearance of a solitary pulmonary metastasis must no longer be regarded as the inevitable harbinger of death, but rather the signal for an intensive period of observation and, if necessary, investigation. Only in this way will suitable patients be given the benefit of further treatment. It is likely that such close surveillance will disclose an even higher proportion of potentially suitable pulmonary lesions, for if untreated all must multiply and later mask the fact that at first a solitary metastasis remained uncomplicated by others for several months, the discovery and treatment of which might have prevented further spread of the disease.

\section{SUMMARY}

1. A series of twelve patients with solitary lung metastases from primary tumours of bone is reviewed. There were seven osteosarcomas, two chondrosarcomas, two fibrosarcomas and one malignant chondroblastoma. In each patient the lung desposit was resected.

2. Four patients have so far died from the disease. The average survival of the others since pulmonary resection is six years and seven months.

3. It is suggested that the results of pulmonary resection in carefully selected patients with solitary pulmonary metastases fully justify the procedure.

4. Careful investigation to ensure as far as possible that the metastasis is solitary, and a " waiting period" in case others should develop, are essential if unnecessary surgery is to be avoided. A waiting period of three months is recommended.

We wish to thank Sir Thomas Holmes Sellors and Mr J. R. Belcher, under whose care the patients were treated at The Middlesex Hospital. Professor Sir Brian Windeyer kindly helped us trace other patients, some of whom had been treated initially by him at The Middlesex Hospital and Mount Vernon Hospital. It is also a pleasure to thank the other thoracic surgeons who have kindly allowed us to include their patients: Mr Charles Drew of the Westminster Hospital, Mr J. W. Jackson of Harefield Hospital, Mr Ian Morrison of Aintree Hospital, Liverpool, and Mr Oswald Tubbs of St Bartholomew's Hospital. Mr F. Radcliffe has kindly allowed us to include his patient (Case 5) previously reported by him at the meeting of the British Orthopaedic Association at Buxton in 1954.

\section{REFERENCES}

Alexander, J., and Haight, C. (1947): Pulmonary Resection for Solitary Metastatic Sarcomas and Carcinomas. Surgery, Gynecology and Obstetrics, 85, 129.

Claget, O. T., and Woolner, L. B. (1964): Surgical Treatment of Solitary Metastatic Pulmonary Lesion. Medical Clinics of North America, 48, 939.

Moersch, R. N., Bickel, W. H., and Clagett, O. T. (1963): Surgical Resection of Pulmonary Metastatic Lesions Secondary to Tumors of the Head, Trunk, or Extremities. Journal of Bone and Joint Surgery, 45-A, 1030.

Sмiтh, F. R. (1963): Resection of Solitary Pulmonary Metastases. Journal of the International College of Surgeons, 40, 606.

VOL. 49 B, NO. 1, FEBRUARY 1967 